\title{
Cloud vs. Legacy ERP Systems Tug of War Intensifies for SMBs
}

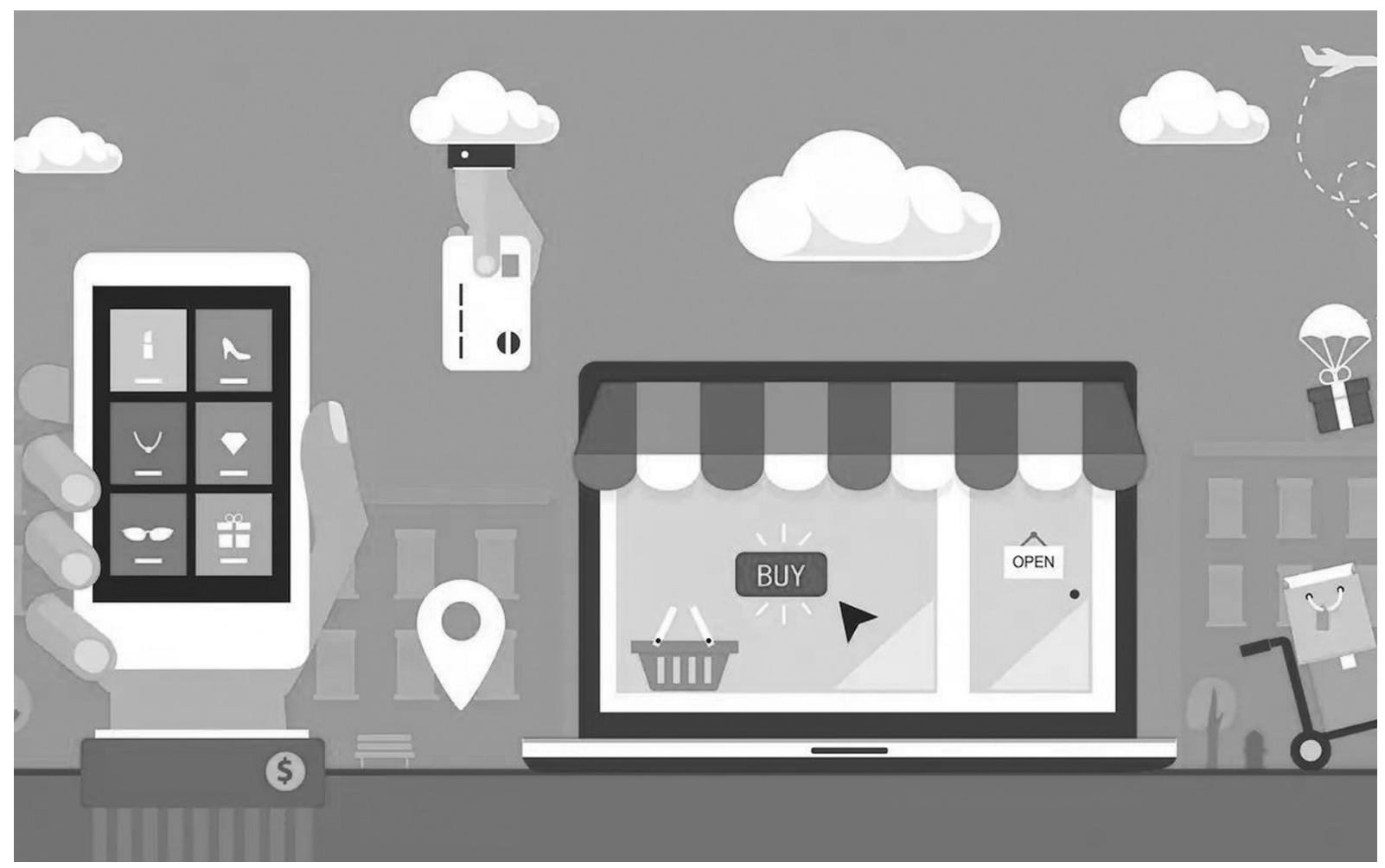

August 2018, Vol. 6, No. 4

Aging legacy ERP systems at SMBs seem to be getting plenty of scrutiny these days. Heightened consumer demands, shifting technology landscapes and relentless market disruptions, not to mention maintenance costs, technical support and obsolescence, can all conspire to keep IT managers up late at night calculating the proper time to upgrade or ditch their "old" ERP systems. Yet, for better or worse, their sleep patterns may be normalizing as decisions to migrate ERP to the cloud are increasingly drifting away from IT and landing on the laps of business leaders.

August's Business Information opens with our editor's note and advice for business and IT decision-makers who are feeling the heat: Don't be myopic when planning a flight to the cloud. The numerous ERP deployment options available to SMBs dictate that immediate company needs must be tempered with an eye toward the future.
Along those lines, our cover story examines the decision-making process when SMBs have to upgrade their legacy ERP systems or move to the cloud -- a migration that SaaS is making more palatable and popular among smaller businesses. In another feature, we drill down into vertical, industry-specific ERP technologies that allow SMBs to cost-effectively make immediate specialty upgrades to their systems.

Also in this issue, a medical device group migrated to cloud ERP primarily because of the expense of adding features and functions to its existing on-premises system. In addition, SMBs face many issues when implementing SaaS ERP operations as Al, big data analytics and smart workflow reach mission-critical levels. And statistics show that cloud ERP ranks ahead of big data analytics, data integration, Al and IoT software initiatives planned for deployment this year, while on-premises ERP packaged business apps are near the bottom of IT's grocery list of priorities 